\title{
Synchronous Measurement and Verification of Position-Independent Geometric Errors and Position-Dependent Geometric Errors in C-Axis on Mill-Turn Machine Tools
}

\author{
Yu-Ta Chen \\ Ting-Yu Lee \\ Chien-Sheng Liu ( $\nabla$ chienshengliu@gmail.com ) \\ National Cheng Kung University https://orcid.org/0000-0002-3537-5828
}

\section{Research Article}

Keywords: Five-axis machine tool, Rotary axis, Geometric errors, Position-independent geometric errors, Position-dependent geometric errors, Touch-trigger probe, Mill-turn machine tool

Posted Date: March 7th, 2022

DOl: https://doi.org/10.21203/rs.3.rs-1398940/v1

License: (c) (i) This work is licensed under a Creative Commons Attribution 4.0 International License.

Read Full License 


\title{
Synchronous Measurement and Verification of Position- \\ Independent Geometric Errors and Position-Dependent \\ Geometric Errors in C-Axis on Mill-Turn Machine Tools
}

\author{
Yu-Ta Chen \\ Department of Mechanical Engineering, Southern Taiwan University of Science and \\ Technology, Tainan, Taiwan
}

Address: No. 1, Nan-Tai Street, Yungkang Dist., Tainan City 710301, Taiwan R.O.C. Tel: +886-6-2533131 ext. $3571 \quad$ Fax: +886-6-2425092

E-mail:YuTaChen@stust.edu.tw

Ting-Yu Lee

Department of Mechanical Engineering, National Cheng Kung University, Taiwan Address: No.1, University Road, Tainan City 70101, Taiwan

E-mail:n16084747@gs.ncku.edu.tw

\section{Chien-Sheng Liu*}

Department of Mechanical Engineering, National Cheng Kung University, Taiwan Address: No.1, University Road, Tainan City 70101, Taiwan Tel: +886-6-2757575 ext. $62114 \quad$ Fax: $+886-6-2352973$

*Corresponding author: csliu@mail.ncku.edu.tw 


\section{Highlights}

- A synchronous measurement system of four position-independent geometric errors (PIGEs) and two position-dependent geometric errors (PDGEs) for the rotary axis in fiveaxis machine tools is proposed in this paper.

- The simulation results also verify the feasibility of this measurement system.

- The measurement method proposed in this paper is actually used in the experiment of a mill-turn machine tool. 


\begin{abstract}
This paper proposes a synchronous measurement system of four position-independent geometric errors (PIGEs) and two position-dependent geometric errors (PDGEs) for the rotary axis in five-axis machine tools. The measuring instruments used in this system are a touchtrigger probe and two standard calibration spheres. The contribution of this paper is the simultaneous measurement of four PIGEs and two PDGEs (axial and angular positioning errors) can be directly analyzed through only one measuring process. It is expected to improve the shortcomings of previous studies that separately measured PIGEs and PDGEs. This paper analyzed the geometric errors of C-axis of a mill-turn machine tool MT-540. The process of calculation includes the establishment of the mathematical model of the machine and geometric error equations. Using the least squares method to solve the linear overdetermined system and calculate the values of the geometric errors. Before solving the geometric errors, the accuracy of the calculated process is ensured by using the simulated method. The simulation results also confirm the feasibility of this measurement system. Then using the data obtained from the experiment to calculate the geometric errors in the machine tool. During the experiment, the calibration procedure of the touch-trigger probe will be calibrated. After the calibration is completed, the mechanical coordinate values of the two standard calibration balls can be measured. The geometric error equations are programmed on the computer side, and the calibration spheres data obtained from the experimental measurement is substituted into the program to calculate the four PIGEs and two PDGEs.
\end{abstract}

Keywords: Five-axis machine tool, Rotary axis, Geometric errors, Position-independent geometric errors, Position-dependent geometric errors, Touch-trigger probe, Mill-turn machine tool 


\section{Introduction}

The demand for the use of five-axis computer numerical control (CNC) machine tools is increasing in recent years[1, 2]. Compared with conventional three-axis machine tools, there are two rotary axes are added in five-axis machine tools, and the movement mode with two more degrees of freedom increases the possibility of processing various curved surfaces[3, 4]. The five-axis machine tools also bring higher efficiency, automation, flexibility, and precision product processing strategy. To improve the accuracy requirements of five-axis machine tools, many manufacturers have turned their research directions to instruments and methods of measuring the rotary axis $[5,6]$. Nowadays, the commercially available products commonly used to measure the geometric errors of the rotary axis of the machine tools are R-Test, QC20W (Ballbar), XR20-W, LaserTRACER, AxiSet Check-Up, SWIVELCHECK, and so on. Improving the accuracy of the rotary axis is a very important. Therefore, this paper focuses on the measurement of the rotary axis of the five-axis machine tools. A touch-trigger probe was used in this paper. Its advantages are that the price is quite affordable, and the accuracy is high. The touch-trigger probe is also quite simple and quick to install. Compared with the a forementioned commercially available instruments, the touch-trigger probe has the advantages of cheaper price, easy-to-handle operating procedures, and high mobility[7,8].

According to previous researches [9-11], the error sources that affect the machining accuracy of machine tools can be divided into three categories: static errors, dynamic errors, and quasi-static errors. Quasi-static errors include thermal errors and geometric errors. According to previous research[12], quasi-static errors account for $70 \%$ of all error sources. According to the research of Xiong and Shen et al. $[13,14]$ to analyze the error source, the geometric error itself accounted for 30\%. The geometric error can be said that it is a crucial factor that affects the accuracy of the machine tools. These all prove that solving the geometric errors can greatly improve the processing quality of the machine tools and modern industries using automated machine tools require high-precision positioning of axis[15, 16]. When high precision is required, it is necessary to solve the problem of accuracy reduction caused by its error. The geometric errors of the rotary axis can be divided into two categories. One is the position independent geometric errors (PIGEs, also called location errors). There are 4 items of PIGEs. Another one is position dependent geometric errors (PDGEs, also called component errors). There are 6 items of PDGEs. From previous researches[8, 17-19], it can be found that these documents only measure the PIGEs of the rotary axis, and it can be observed from other documents that they mainly analyze the PDGEs of the rotary axis [20-22]. However, the PIGEs and the PDGEs affect the rotary axis of the machine tools at the same time, so this paper hopes to consider the PDGEs into the calculation of the PIGEs simultaneously. According to the literature $[23,24]$, angular positioning error is the most important among the 6-degree-offreedom PDGEs of the rotary axis. The positioning accuracy of the rotary axis is an important 
indicator for evaluating the performance of the rotary axis. Therefore, the purpose of this paper is to analyze the 4 PIGEs and 2 PDGEs (angular positioning and axial errors) of the rotary axis of the machine tools at the same time.

Jeong et al. used a touch-trigger probe to measure all the PIGEs of a four-axis machine tool. The research method uses 2 standard calibration spheres and a touch-trigger probe to measure and uses the height difference of the two spheres to obtain additional information to calculate the errors[25]. However, since the height of the calibration sphere in the calculation formula is an important piece of information, when the height measurement is inaccurate, it will greatly affect the measurement values of the PIGEs. Chen et al. used a touch-trigger probe with a standard calibration sphere to measure a five-axis machine tool and calculate a total of 8 PIGEs of dual-rotary axes [26]. The operation process is fast and requires only one calibration sphere, so the measurement efficiency is high, and the operation is simple and convenient. However, in the calculation process of this method, the PDGEs of the rotary axis is not considered at the same time. Therefore, when the PDGEs is omitted and only the PIGEs are considered, the error values will be slightly inaccurate.

It is also an error measurement method to process a workpiece online, and to measure the geometric information of the workpiece to calculate the geometric errors. Ibaraki [27], Li [28] and Jiang et al. [29] have all proposed a method of measuring geometric errors by online machining a special-shaped workpiece on a machine, and the method of online processing can include the impact of the thermal error during machining in the geometric characteristics of the workpiece. However, the disadvantage of online processing is that the use of cutting will increase many error causes, such as the influence of cutting force, which will cause the accuracy of the original measurement target to decrease. Ibaraki also proposed other geometric shapes such as squares and used touch-trigger probes for geometric error measurement [8]. He also proposed using special geometric shapes and rotating the rotary axis in different paths to measure different items of the geometric errors.

From the literature review, it can be found that the geometric error measurement method mainly needs to use the spindle and the movement of each component to touch the standard part, or the processed workpiece placed on the worktable to calculate the values of errors. Since the errors of the measured axis will manifest itself in the object to be measured or cause changes in the trajectory when moving, so many researches used this method above to calculate the errors. The difference between these researches is that the geometry of the object to be measured is different and the path difference of the moving axis can measure the error of the different axis. The purpose and contribution of the paper is to analyze the 4 PIGEs and 2 PDGEs (angular positioning and axial errors) of the rotary axis of the machine tools simultaneously.

\section{System structure and measurement principle}




\subsection{Definition of geometric errors}

Geometric errors can be divided into two categories [30, 31]. According to ISO230-1 [32] and ISO230-7[33], geometric errors are defined as PIGEs and PDGEs. PIGEs are the offset when the assembly is inaccurate. These values are fixed value and will not change with the movement of the axis. Due to the manufacturing deviation of machine tool parts, each axis cannot move to the ideal position when it shifts. The ideal drive position given by the controller is not exactly the same as the actual moving position everywhere. This difference is the PDGEs.

Table 1. All geometric errors of rotary axis of machine tools.

\begin{tabular}{|c|c|c|c|}
\hline \multicolumn{2}{|r|}{ Symbols used in this thesis } & \multicolumn{2}{|l|}{ ISO } \\
\hline \multirow{4}{*}{$\begin{array}{c}\text { PIGEs } \\
\text { (Rotary } \\
\text { Axis) }\end{array}$} & $\begin{array}{c}\boldsymbol{O}_{x c} \\
\text { (Linear offset error of C-axis in X direction) }\end{array}$ & \multirow{4}{*}{$\begin{array}{c}\text { Location } \\
\text { Errors } \\
\text { (Rotary Axis) }\end{array}$} & $\mathrm{XOC}$ \\
\hline & $\begin{array}{c}\boldsymbol{O}_{\boldsymbol{y c}} \\
\text { (Linear offset error of C-axis in Y direction) }\end{array}$ & & YOC \\
\hline & $\begin{array}{c}\boldsymbol{S}_{x c} \\
\text { (Squareness error of C-axis to Y-axis) }\end{array}$ & & $\mathrm{AOC}$ \\
\hline & $\begin{array}{c}S_{y c} \\
\text { (Squareness error of C-axis to X-axis) }\end{array}$ & & $\mathrm{BOC}$ \\
\hline \multirow{6}{*}{$\begin{array}{c}\text { PDGEs } \\
\text { (Rotary } \\
\text { Axis) }\end{array}$} & $\begin{array}{c}\boldsymbol{\delta}_{x c} \\
\text { (Radial error) }\end{array}$ & \multirow{6}{*}{$\begin{array}{c}\text { Component } \\
\text { Errors } \\
\text { (Rotary Axis) }\end{array}$} & EXC \\
\hline & $\begin{array}{c}\quad \boldsymbol{\delta}_{\boldsymbol{y c}} \\
\text { (Radial error) }\end{array}$ & & EYC \\
\hline & $\begin{array}{c}C_{z(d e p)} \\
\text { (Axial error) }\end{array}$ & & $\mathrm{EZC}$ \\
\hline & $\begin{array}{c}\boldsymbol{\varepsilon}_{x c} \\
\text { (Tilt error) }\end{array}$ & & EAC \\
\hline & $\begin{array}{c}\boldsymbol{\varepsilon}_{y c} \\
\text { (Tilt error) }\end{array}$ & & EBC \\
\hline & $\begin{array}{c}\boldsymbol{C}_{(\text {pos })} \\
\text { (Angular positioning error) }\end{array}$ & & $\mathrm{ECC}$ \\
\hline
\end{tabular}

There are two offset errors and two squareness errors in the PIGEs of a rotary axis. The meaning is that the deviation of the ideal axis center and the actual axis center of the rotary axis has 4 degree-of-freedom errors. According to ISO230-7 [33], the PDGEs of the rotary axis are 6 degrees of freedom, which are 2 radial errors, 1 axial error, 2 tilt errors in two oblique directions, and 1 angular positioning error. This paper focuses on the synchronous 
measurement of the 4 PIGEs of the rotary axis and 2 PDGEs (angular positioning and axial errors) in rotary axis. Table 1 is a list of all geometric errors of the rotary axis and the red frame marks the focus of this paper.

\subsection{Measured five-axis machine tool}

The five-axis machine tool used in this paper is the mill-turn machine tool MT-540 (YIDA PRECISION MACHINERY CO., LTD). as shown in Fig. 1. Its configuration belongs to the RTTTR configuration, which can also be called Table/Spindle-tilting Type and is a five-axis machine tool with $\mathrm{BC}$ axis. The special feature of this machine tool is that it can be used in lathe mode or converted to milling mode. Some products need to be processed by lathes and milling process. This kind of machine tool can complete all the processing procedures in one clamping and improve efficiency. Table 2 shows the specifications of MT-540, and Fig. 2 is a schematic diagram of the position of each axis of the MT-540. The B-axis is also the spindle. For this paper, the touch-trigger probe was locked on the $\mathrm{B}$-axis. The measured $\mathrm{C}$-axis faces the left side of the machine. The main moving range of the spindle is near the $\mathrm{C}$-axis worktable, so the stroke of the linear axes is also around this area. Compared with the general machine tools, the stroke of the $\mathrm{X}, \mathrm{Y}$, and $\mathrm{Z}$ axes is quite short. The $\mathrm{X}$-axis, Y-axis, and Z-axis strokes are 660,200 , and $760 \mathrm{~mm}$, respectively. Because the touch-trigger probe relies on the linear axis for translation, the short stroke cause the limited measurement range. This is also a problem which must be overcome in this paper.

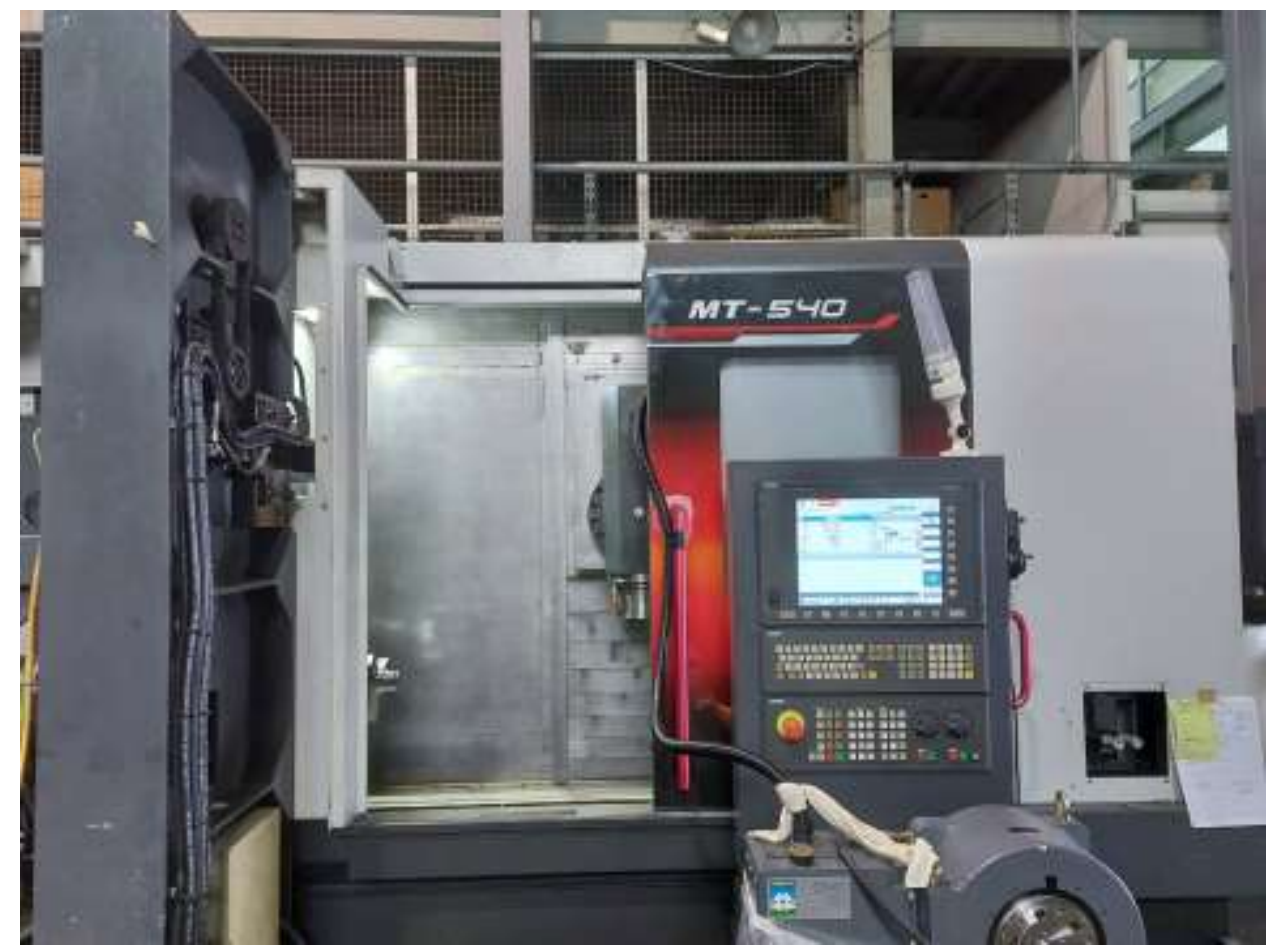

Fig. 1. Mill-turn machine tool MT-540. 
Table 2. MT-540 Specifications.

\begin{tabular}{|c|c|c|}
\hline Type & MT-540 & Unit \\
\hline Tool holder & KM 63UT & \\
\hline Stroke & & degrees \\
\hline B-axis & $\pm 110^{\circ} / 0.001^{\circ}$ & degrees \\
\hline C-axis & $360^{\circ} / 0.001^{\circ}$ & mm (in.) \\
\hline X-axis & $660\left(26.0^{\prime \prime}\right)$ & $\mathrm{mm}$ (in.) \\
\hline Y-axis & $200\left(7.87^{\prime \prime}\right)$ & $\mathrm{mm}$ (in.) \\
\hline Z-axis & $760\left(29.9^{\prime \prime}\right)$ & $\mathrm{mm}$ (inch) \\
\hline Machine size & $4,700\left(185^{\prime \prime}\right)$ & $\mathrm{mm}$ (inch) \\
\hline Length & $2,800\left(110.2^{\prime \prime}\right)$ & $\mathrm{mm}$ (inch) \\
\hline Width & $2700\left(106.3^{\prime \prime}\right)$ & \\
\hline Height & &
\end{tabular}

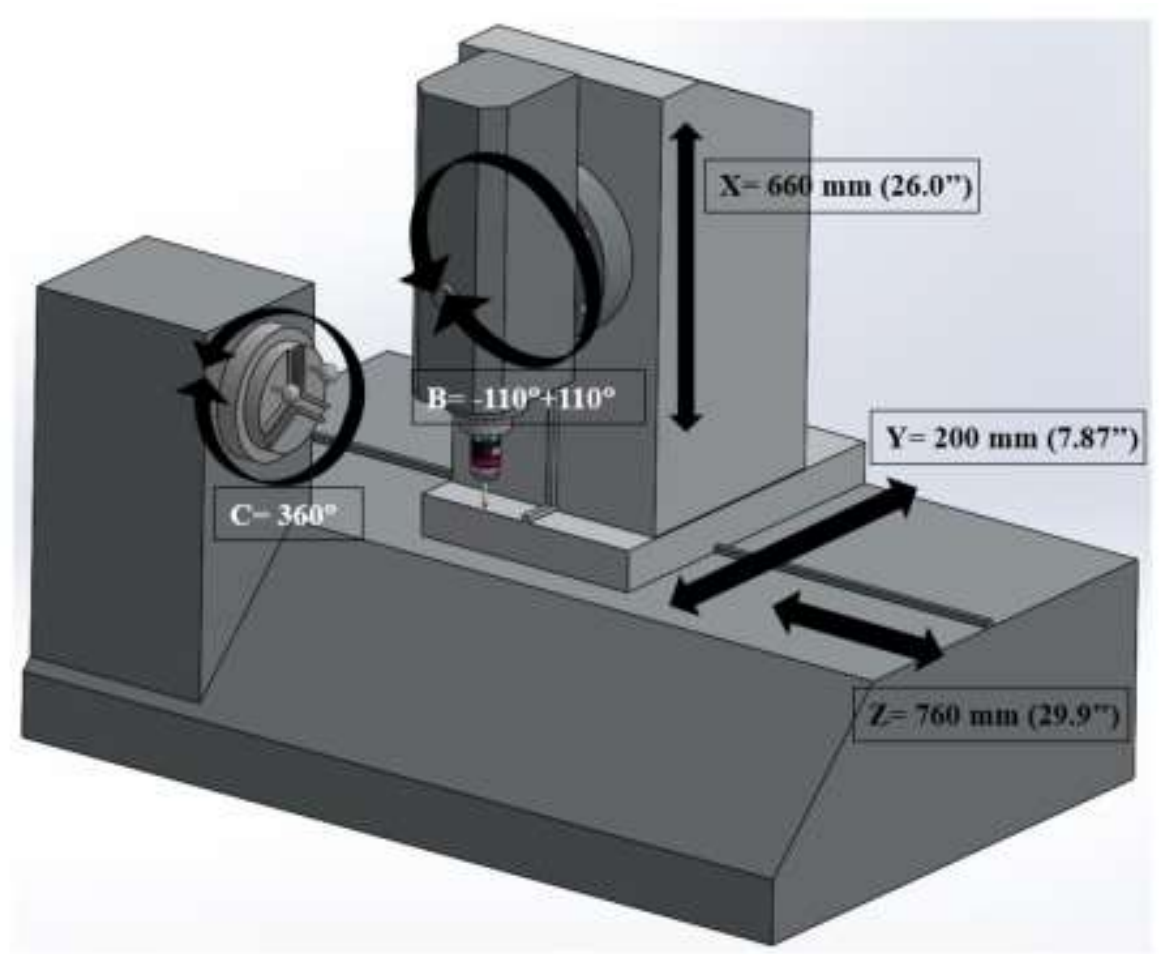

Fig. 2. Schematic diagram of MT-540.

\subsection{Mounting of proposed measurement system}


Table 3. Specifications of touch-trigger probe Blum TC50.

\begin{tabular}{|c|c|}
\hline Type & Blum TC50 \\
\hline Protection class & IP68 \\
\hline Approach direction & $\pm \mathrm{X}, \pm \mathrm{Y},-\mathrm{Z}$ \\
\hline Measuring force in X and Y directions \\
Measuring force in Z direction & $7 \mathrm{~N}$ \\
\hline Max deflection in X and Y directions & $\pm 15^{\circ}$ \\
Max deflection in Z direction & $10 \mathrm{~mm}$ \\
\hline Max acceleration & $50 \mathrm{~m} / \mathrm{s}^{2}$ \\
\hline Repeatability & $0.3 \mu \mathrm{m} 2 \sigma$ \\
\hline Max probing speed & $3 \mathrm{~m} / \mathrm{min}$ \\
\hline Mass & $925 \mathrm{~g}$ \\
\hline Signal transmission & Infrared \\
Range & $\pm 60^{\circ}$ in $\mathrm{Z}, 360^{\circ}$ in X $/ \mathrm{Y}$ \\
\hline Storage temperature & $-20^{\circ} \mathrm{C} \ldots+70^{\circ} \mathrm{C}$ \\
Operating temperature & $+5^{\circ} \mathrm{C} \ldots+50^{\circ} \mathrm{C}$ \\
\hline
\end{tabular}

A Blum TC50 touch-trigger probe was used in this paper. Table 3 shows the specifications of the touch-trigger probe. The touch-trigger probe also needs a tool holder KM63, as illustrated in Fig. 3. Due to the need of the measurement method, this paper requires two standard calibration spheres (two tungsten carbide spheres with a diameter of $18.999 \mathrm{~mm}$ ) for measurement. As shown in Fig. 4, the two calibration spheres were attached to the table of the machine tool. However, as mentioned in section 2.2, because the stroke of the linear axis is too narrow, it can only move around the $\mathrm{C}$-axis table, resulting in the limited measurement range. Using the method shown in Fig. 4 will cause the $\mathrm{C}$-axis to rotate at a severely limited angle. Therefore, the standard calibration sphere cannot be triggered by the probe when rotating a little angle, which affects the process of measurement error.

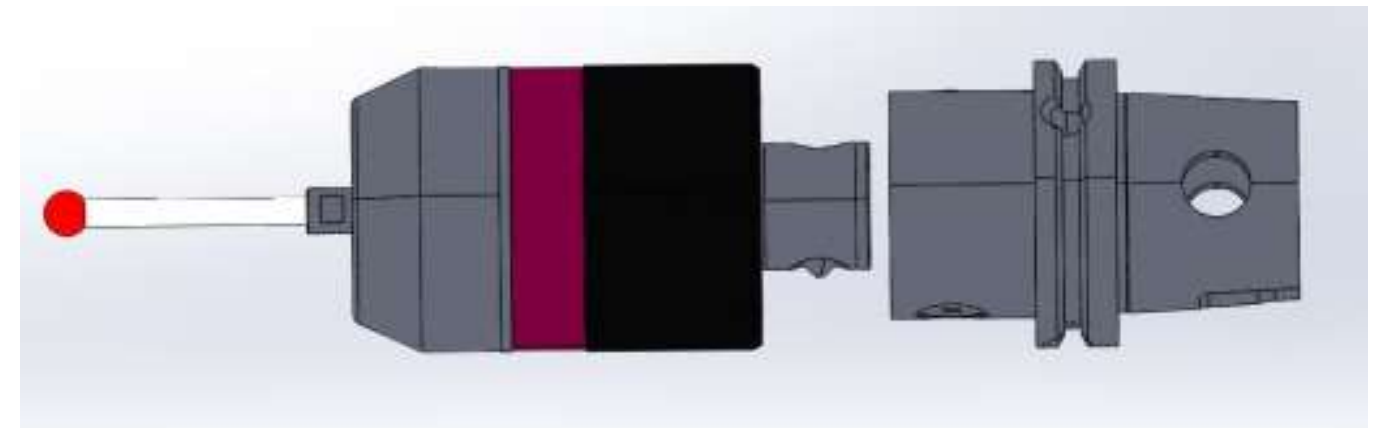

Fig. 3. Schematic diagram for connection between touch-trigger probe TC50 and KM63 tool holder. 


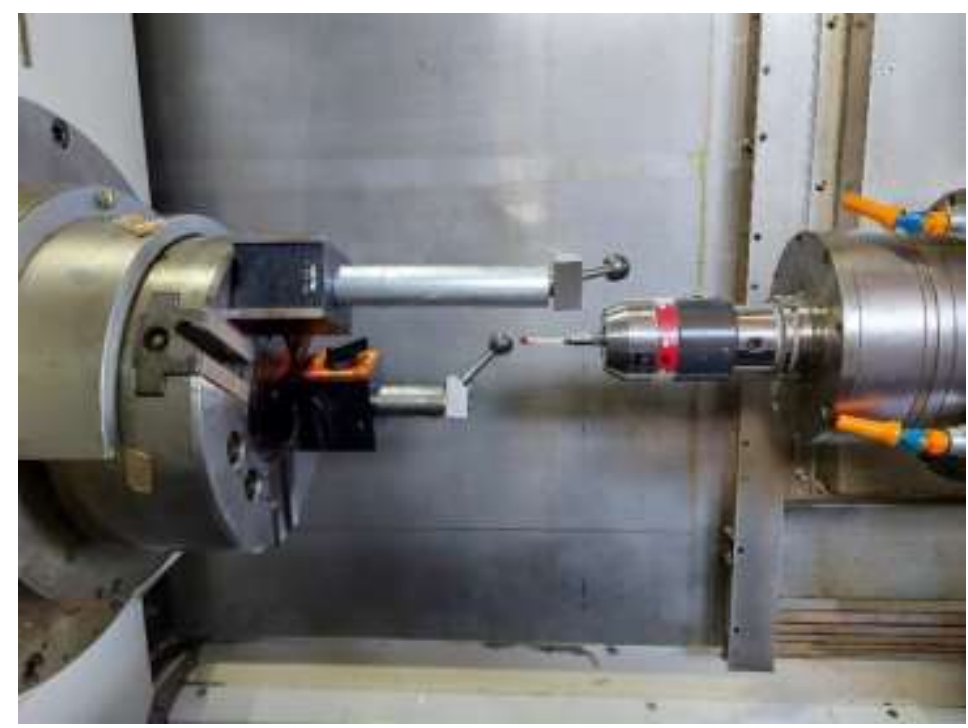

Fig. 4. Measurement experiment diagram using two standard calibration spheres.

To solve the problem of the measurement range, a specific jig was designed. Consider the distance the probe will move when measuring, lock the calibration spheres on the specific jig (see Fig. 5), and then attach it to the C-axis table.

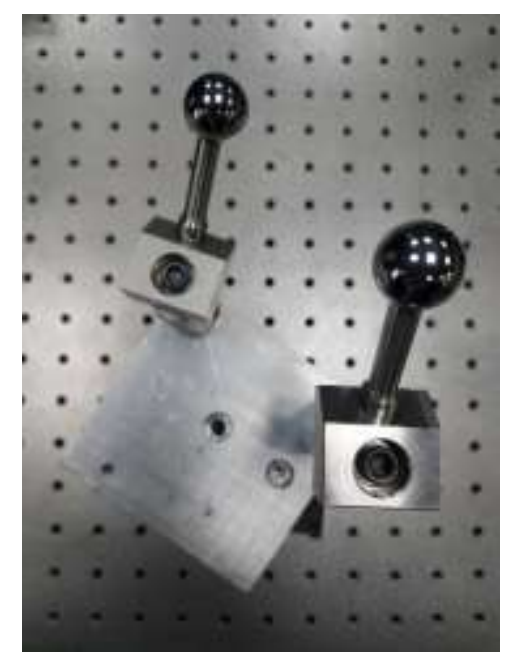

Fig. 5. Lock the jig with two calibration spheres.

\subsection{Measurement objectives and principle}

The measurement objectives of this paper are 4 PIGEs and 2 PDGEs (angular positioning and axial errors), analyzed simultaneously, as shown in Table 1, and the red frame is the measurement target of this study.

The measurement principle of using the standard calibration spheres mainly needs the element that the diameter $18.999 \mathrm{~mm}$ of the calibration spheres is quite accurate. This diameter 
can be used to calculate the values of the mechanical coordinate system of the center of the sphere in the machine tool. Five positions of the calibration sphere were touched to calculate the center coordinates of the sphere, as shown in Fig. 6. As shown in Fig. 7, when the calibration sphere is in the initial position, then the $\mathrm{C}$-axis rotates by an angle. Due to the geometric errors of the $\mathrm{C}$-axis, the axis of the $\mathrm{C}$-axis is offset, resulting in a difference (dP) between the ideal and the actual coordinates of the calibration sphere. With $\mathrm{dP}$, the mathematical equations can be listed, and the geometric errors can be solved by mathematical methods.

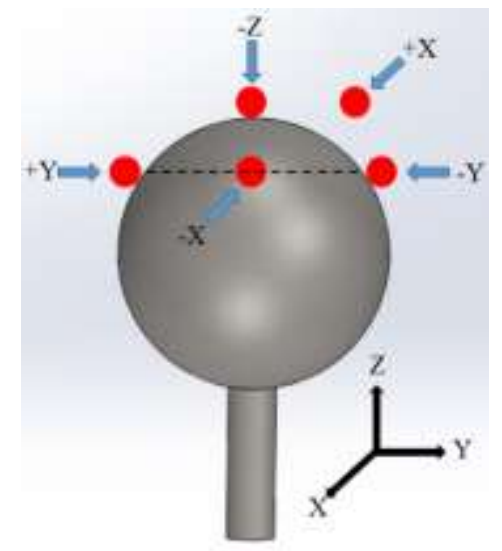

Fig. 6. Measurement of center coordinates of the standard calibration sphere.

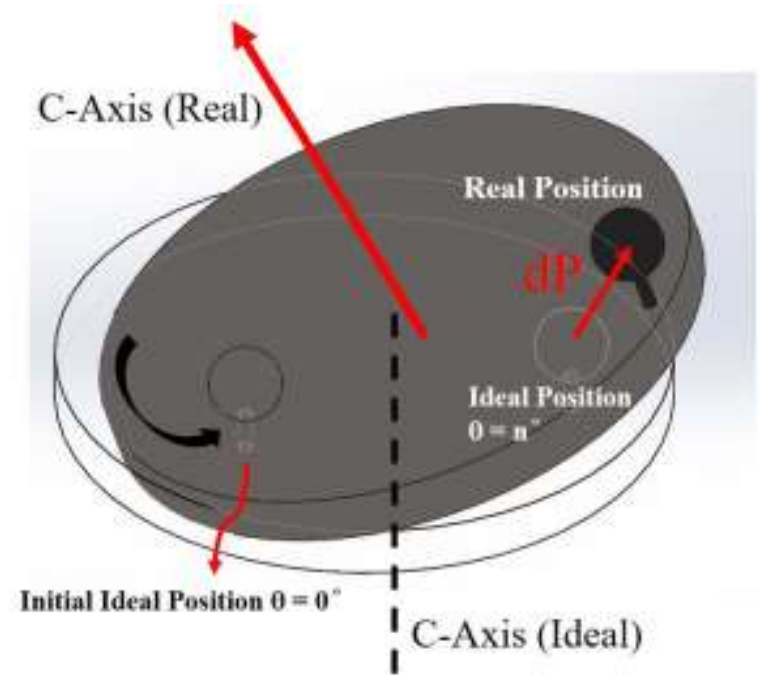

Fig. 7. Difference between ideal and actual coordinates of calibration sphere.

The method of using the calibration sphere to establish the equations is shown in Fig. 8. The $0^{\circ}$ of $\mathrm{C}$-axis is the first position, which is the starting point of the measurement. The gray ball is the point with no error in the first position. The blue circle in the figure is the path of the standard calibration sphere when there is no error in the ideal. When the $\mathrm{C}$-axis rotates, there will be black ball 2 position, black ball 3 position, black ball 4 position and so on. After the C- 
axis rotates, there will be geometric errors. The method of establishing the equations of $\mathrm{dP}$ is shown in Table 4 will subtract the first ideal position from the second position, subtract the first ideal position from the third position, and subtract the first ideal position from the fourth position. After multiple sets of $\mathrm{dP}$ equations are listed, $\mathrm{dP}$ is used to analyze the error values.

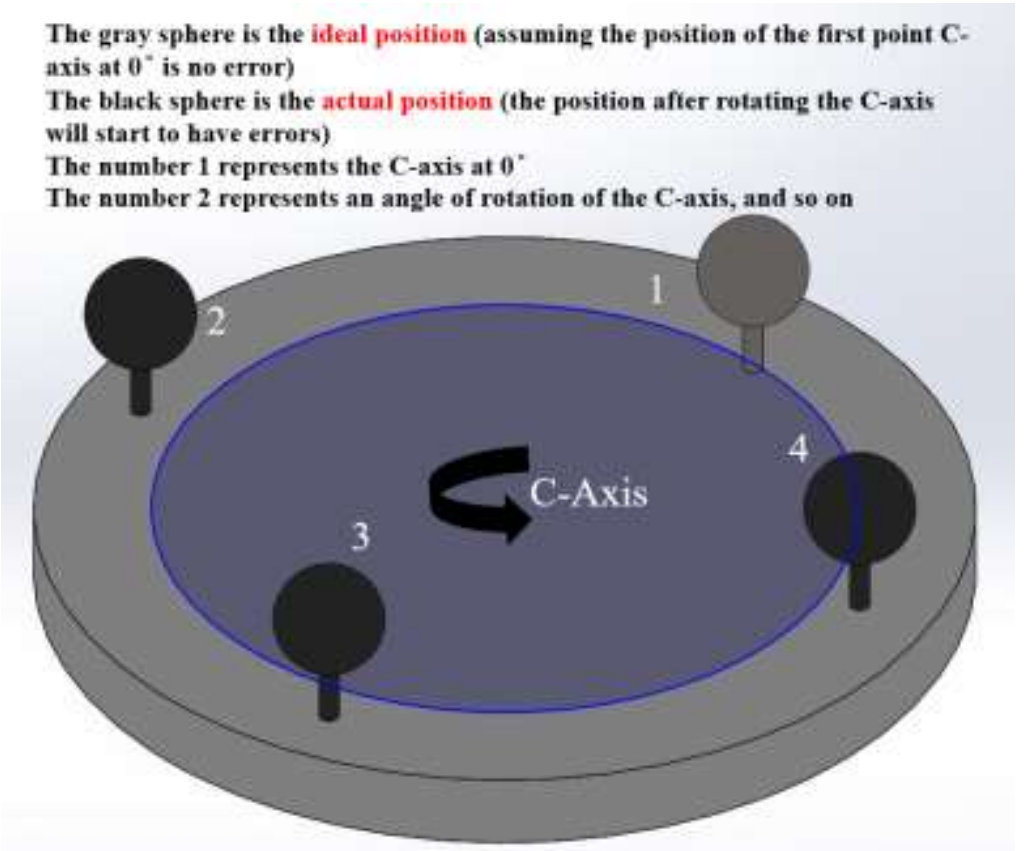

Fig. 8. Schematic diagram for method of establishing equations.

Table 4. The method of establishing equations of dP.

\begin{tabular}{|c|c|}
\hline $\mathrm{dP} 1$ & 2nd position-1st ideal position \\
\hline $\mathrm{dP} 2$ & 3rd position-1st ideal position \\
\hline $\mathrm{dP} 3$ & 4th position-1st ideal position \\
\hline$\ldots$ & $\ldots$ \\
\hline
\end{tabular}

\section{Establishment of geometric error model}

\subsection{Forward kinematics}

The significance of forward kinematics is that after the forward kinematics is continuously multiplied by each matrix of the homogeneous transformation matrix, when the drive values of each axis, namely the servo commands $x_{c m}, y_{c m d}, z_{c m d}$ are known, the final pose matrix can be calculated by mathematical model. For machine tools, it is the coordinates of the touchtrigger probe relative to the reference coordinate system and the coordinates of the standard calibration spheres relative to the reference coordinate system. On the other hand, inverse kinematics is to push back the servo commands $x_{c m}, y_{c m d}, z_{c m d}$ of each axis when the pose 
matrix is known, as shown in Fig. 9.

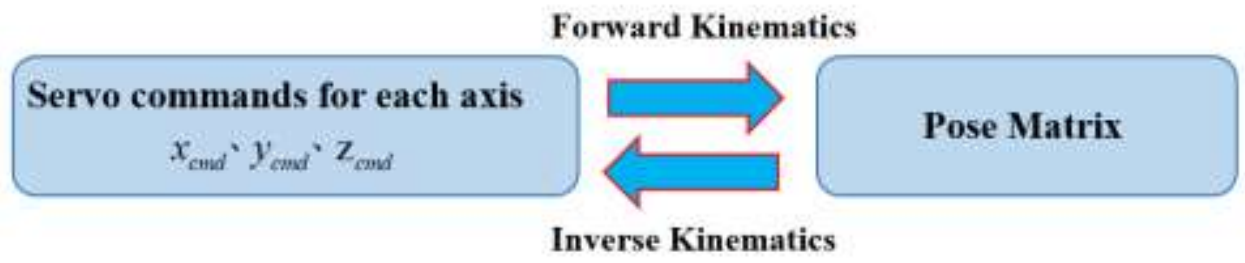

Fig. 9. Illustration of forward and reverse kinematics.

The machine used in this paper is a mill-turn machine tool. The total components are Caxis (rotary axis), spindle (touch-trigger probe), B-axis (rotary axis), X-axis, Y-axis, and Z-axis. Our purpose is to find the relationship between the probe and the standard calibration spheres, so two kinematic chains, namely the probe kinematic chain and the calibration sphere kinematic chain, need to be constructed. From Fig. 2 , it can be seen that $\mathrm{C}$-axis is a workbench, which is erected on the left side of the machine tool, and the standard calibration spheres are attracted to the end of the $\mathrm{C}$-axis.

The kinematic chain of touch-trigger probe: reference coordinate system $R \rightarrow Z \rightarrow Y \rightarrow X \rightarrow$ $\mathrm{B} \rightarrow \mathrm{P}$ (touch-trigger probe). The standard calibration sphere kinematic chain: reference coordinate system $\mathrm{R} \rightarrow \mathrm{C} \rightarrow \mathrm{S}$ (standard calibration sphere). Using these two kinematic chains to find the correlation between the probe and the calibration sphere. Since the measurement object of this paper is C-axis, the rotary B-axis does not rotate in this paper and the geometric errors of B-axis is not considered here. The construction of forward kinematics first needs to use the homogeneous transformation matrix (HTM) to complete the error model.
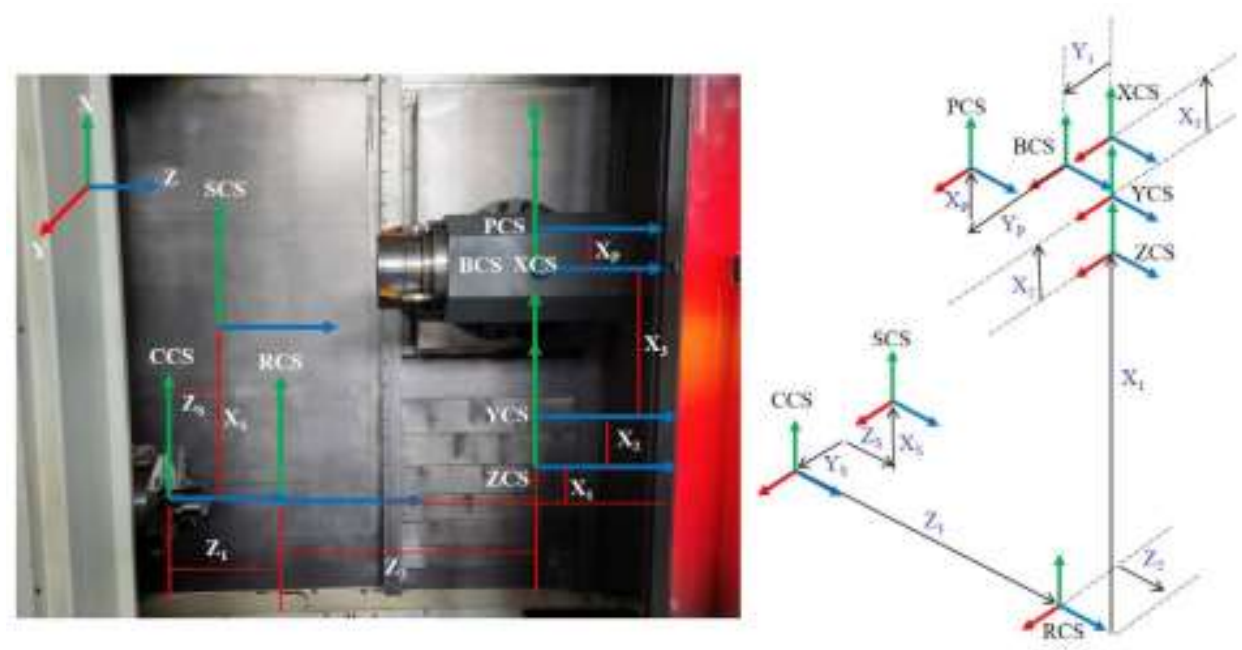

Fig. 10. Coordinate system of each axis of mill-turn machine tool. 
When using HTM to build a geometric error model for a machine tool, a coordinate system of each axis of the machine tool must be created. Fig. 10 illustrates the coordinate system of each axis of the mill-turn machine tool and then each coordinate system is connected into the two kinematic chains through HTM. The HTM of the coordinate system of C-axis relative to the reference coordinate system $\mathrm{R}$ is ${ }^{R} T_{C}$, and ${ }^{R} T_{C}=T^{c o} T^{c s} T^{c(d e p)} T^{c}$. Since C-axis is the measured axis, the analyzed errors need to be put in the matrix. $T^{c o}$ is the offset error matrix in the PIGEs of C-axis, and $T^{c s}$ is the squareness Error matrix in the PIGEs of C-axis. $T^{c(d e p)}$ means the PDGEs of C-axis, and $T^{c}$ is the drive of C-axis by the controller. $\theta_{c}$ is the servo command value of C-axis. $O_{x c}, O_{y c}, S_{x c}$, and $S_{y c}$ are the 4 PIGEs of C-axis. $C_{z(d e p)}$ and $C_{(p o s)}$ are the axial error and angular positioning error, respectively, in the PDGEs of $\mathrm{C}$-axis. The result of multiplying all error matrices is ${ }^{R} T_{C}$ as Eq. (1).

$$
\begin{aligned}
& T^{c o}=\left[\begin{array}{cccc}
1 & 0 & 0 & O_{x c} \\
0 & 1 & 0 & O_{y c} \\
0 & 0 & 1 & 0 \\
0 & 0 & 0 & 1
\end{array}\right] \quad T^{c s}=\left[\begin{array}{cccc}
1 & 0 & S_{y c} & 0 \\
0 & 1 & -S_{x c} & 0 \\
-S_{y c} & S_{x c} & 1 & 0 \\
0 & 0 & 0 & 1
\end{array}\right] \quad T^{c(d e p)}=\left[\begin{array}{cccc}
1 & 0 & 0 & 0 \\
0 & 1 & 0 & 0 \\
0 & 0 & 1 & C_{z(d e p)} \\
0 & 0 & 0 & 1
\end{array}\right] \\
& T^{c}=\left[\begin{array}{cccc}
\cos \left(\theta_{c}+C_{(p o s)}\right) & \sin \left(\theta_{c}+C_{(p o s)}\right) & 0 & 0 \\
-\sin \left(\theta_{c}+C_{(p o s)}\right) & \cos \left(\theta_{c}+C_{(p o s)}\right) & 0 & 0 \\
0 & 0 & 1 & 0 \\
0 & 0 & 0 & 1
\end{array}\right] \\
& \begin{array}{c}
{ }^{R} T_{C}= \\
{\left[\begin{array}{cccc}
\cos \left(\theta_{c}+C_{(p o s)}\right) & \sin \left(\theta_{c}+C_{(p o s)}\right) & S_{y c} & O_{x c}+C_{z(d e p)} S_{y c} \\
-\sin \left(\theta_{c}+C_{(p o s)}\right) & \cos \left(\theta_{c}+C_{(p o s)}\right) & -S_{x c} & O_{y c}-C_{z(d e p)} S_{x c} \\
-S_{y c} \cos \left(\theta_{c}+C_{(p o s)}\right)-S_{x c} \sin \left(\theta_{c}+C_{(p o s)}\right) & S_{x c} \cos \left(\theta_{c}+C_{(p o s)}\right)-S_{y c} \sin \left(\theta_{c}+C_{(p o s)}\right) & 1 & C_{z(d e p)} \\
0 & 0 & 0 & 1
\end{array}\right]}
\end{array}
\end{aligned}
$$

${ }^{R} T_{Z},{ }^{Z} T_{Y},{ }^{Y} T_{X},{ }^{X} T_{B},{ }^{B} T_{P}$ are the matrices in the kinematic chain of the touch-trigger probe, and ${ }^{R} T_{C},{ }^{C} T_{S}$ are the matrices in the kinematic chain of the standard calibration spheres. Then the HTM of probe coordinate system P relative to the reference coordinate system R and the HTM of the calibration sphere coordinate system S relative to the reference coordinate system $\mathrm{R}$ are constructed, respectively, as shown in Eq. (2) and Eq. (3). 


$$
\begin{aligned}
& { }^{R} T_{P}={ }^{R} T_{Z}{ }^{\mathrm{Z}} T_{Y}{ }^{{ }^{Y}} T_{X}{ }^{X} T_{B}{ }^{B} T_{P} \\
& { }^{R} T_{S}={ }^{R} T_{C}{ }^{C} T_{S}
\end{aligned}
$$

\subsection{Inverse kinematics}

Section 3.1 introduced the touch-trigger probe kinematic chain and the standard calibration sphere kinematic chain in the mathematical model. For inverse kinematics, these two kinematic chains can be used to calculate the servo commands of the three linear axes. Because the touchtrigger probe will touch the standard calibration spheres, the values of the mechanical coordinate system of the spheres can be calculated. In other words, the two kinematic chains will collide with each other. Therefore, the coordinate values of the probe relative to the reference coordinate system and the calibration sphere relative to the reference coordinate system are the same, and the servo command can be calculated by using this feature.

The ideal servo command symbols are $x_{c m d}^{i}, y_{c m d}^{i}$, and $z_{c m d}^{i}$ as Eq. (4) to Eq. (6), respectively. The solved actual servo command symbols are $x_{c m d}^{r}, y_{c m d}^{r}$, and $z_{c m d}^{r}$ as Eq. (7) to Eq. (9) , respectively. The solution result contains many quadratic terms, which means that there are many errors' multiplied terms in the servo command equations, but the values of these terms are quite small. Therefore, Eq. (7) to Eq. (9) are the results after omitting the quadratic term, and $x_{s}, y_{s}$, and $z_{s}$ are the coordinates of the calibration sphere coordinate system (S) relative to $\mathrm{C}$-axis coordinate system.

$$
\begin{gathered}
x_{c m d}^{i}=x_{s} \cos \left(\theta_{c}\right)+y_{s} \sin \left(\theta_{c}\right) \\
y_{c m d}^{i}=y_{s} \cos \left(\theta_{c}\right)-x_{s} \sin \left(\theta_{c}\right) \\
z_{c m d}^{i}=-z_{2}+z_{s} \\
x_{c m d}^{r}=O_{x c}+z_{s} S_{y c}+x_{s} \cos \left(\theta_{c}\right)+y_{s} C_{(p o s)} \cos \left(\theta_{c}\right)+y_{s} \sin \left(\theta_{c}\right)-x_{s} C_{(p o s)} \sin \left(\theta_{c}\right) \\
y_{c m d}^{r}=O_{y c}-z_{s} S_{x c}+y_{s} \cos \left(\theta_{c}\right)-x_{s} C_{(p o s)} \cos \left(\theta_{c}\right)+x_{s} \sin \left(\theta_{c}\right)-y_{s} C_{(p o s)} \sin \left(\theta_{c}\right) \\
z_{c m d}^{r}=-z_{2}+z_{s}+C_{z(d e p)}+y_{s} S_{x c} \cos \left(\theta_{c}\right)-x_{s} S_{y c} \cos \left(\theta_{c}\right)-x_{s} S_{x c} \sin \left(\theta_{c}\right)-y_{s} S_{y c} \sin \left(\theta_{c}\right)
\end{gathered}
$$

\subsection{Assumptions of geometric error variables}

There is a fundamental difference between PIGEs and PDGEs, as shown in Table 5. The values of PIGEs are the same in each angle of the rotary axis and will not cause the values of errors to change with the rotation of the rotary axis; the PDGEs are originally the error values when measuring each angle of the rotary axis, so the PDGEs are different when the rotary axis rotates at each angle. To analyze the key points of PIGEs and PDGEs simultaneously, this factor must be taken into account in the analysis of the equations. 
Table 5. Difference between PIGEs and PDGEs.

\begin{tabular}{|c|c|}
\hline \multicolumn{2}{|c|}{ Difference between PIGEs and PDGEs } \\
\hline PIGEs & PDGEs \\
\hline $\begin{array}{c}\text { When the rotary axis rotates once, the } \\
\text { PIGEs of each position in rotary axis is } \\
\text { a fixed value }\end{array}$ & $\begin{array}{c}\text { When the rotary axis rotates once, the } \\
\text { PDGEs of each position is different }\end{array}$ \\
\hline
\end{tabular}

In this paper, the servo commands $x_{c m d}, y_{c m d}$, and $z_{c m d}$ were used to establish the equations through inverse kinematics. When $\mathrm{C}$-axis rotates at different angles, the two variables $C_{z(d e p)}$ and $C_{(p o s)}$ will continue to change signs in the process of analyzing equations in this paper. For example, the next angle of $C_{z(d e p)}$ and $C_{(p o s)}$ becomes $C_{z(d e p) 2}, C_{(p o s) 2}$ and so on. The PDGEs variables of each equation continue to change, but the PIGEs remain unchanged. Finally, the equations of all the measured angles of $\mathrm{C}$-axis were established and analyzed together. This is the method of this paper to measure the PIGEs and the PDGEs at the same time.

\section{Measurement method and error calculation result}

\subsection{Measurement method and experiments}

Before the experiment, a calibration process of the touch-trigger probe was executed. The calibration of the probe can ensure that this experiment is not affected by the errors of the probe. After the calibration is completed, the operation process of measuring the coordinates of the standard calibration spheres can be started.

As stated in Section 2.3, two standard calibration spheres were used as the tested object. During the experiment, firstly only the $\mathrm{C}$-axis is rotated. After the $\mathrm{C}$-axis is rotated to the next angle, the linear axis was used to move the touch-trigger probe to the vicinity of the calibration spheres and touch the 5 points of spheres and calculate the coordinates of the center of the spheres. After measuring the first sphere, use the linear axis to move to the vicinity of the second sphere to measure its coordinates. After measuring both spheres, $\mathrm{C}$-axis was rotated to the next angle. The measurement process and experimental setup are shown in Figs. 11 and 12, respectively. 


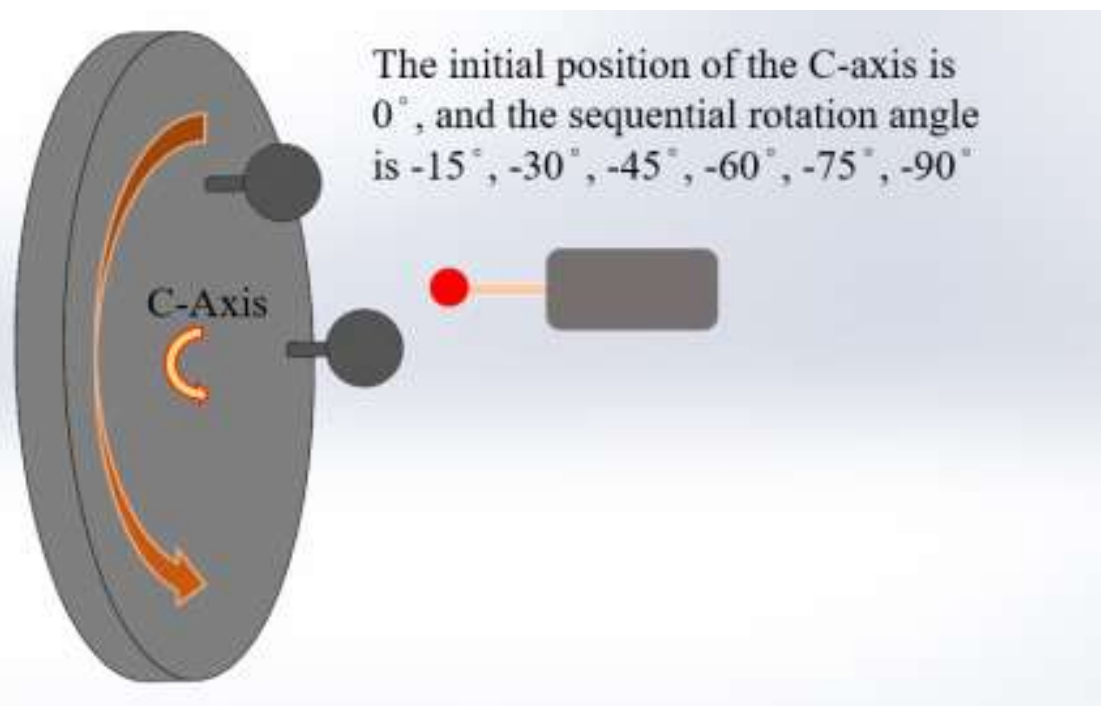

Fig. 11. Schematic diagram of measurement path of C-axis.

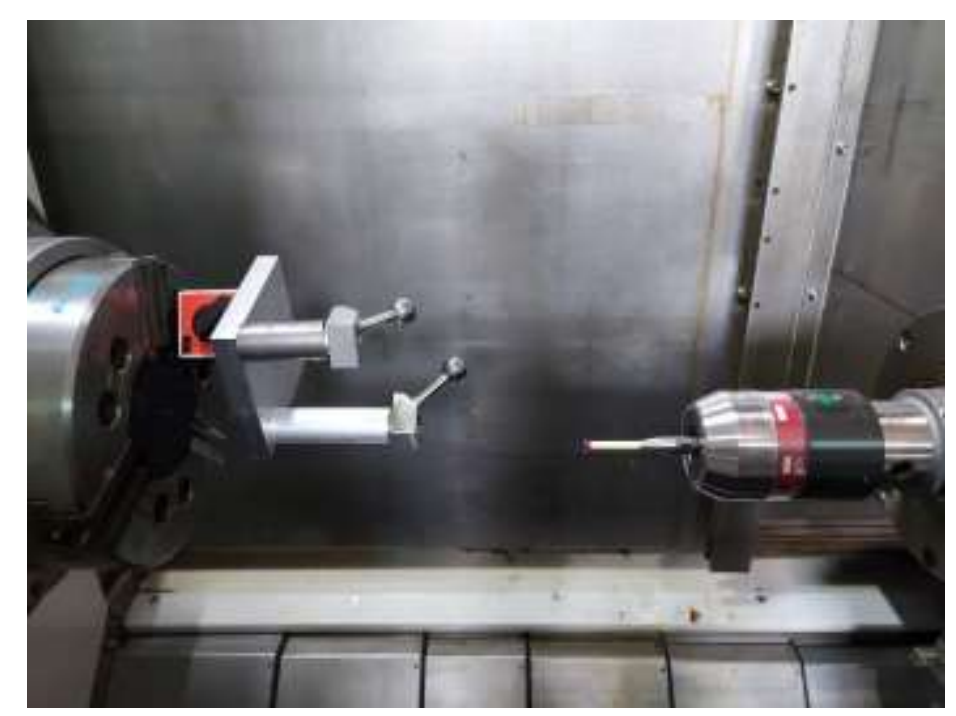

Fig. 12. Photograph of measurement process.

\subsection{Method of Geometric error calculation}

In this section, the least squares method was used to analyze the error values through the equations introduced in section 2.4. The servo command $x_{c m d}^{r}, y_{c m d}^{r}$, and $z_{c m d}^{r}$ of the calibration spheres with the error when the $\mathrm{C}$-axis rotates by each angle minus the servo command when the $\mathrm{C}$-axis is at $0^{\circ}$, and the error $\mathrm{dP}$ can be listed as shown in Table 4 . The position at $0^{\circ}$ is assumed to be no error. The purpose of using the least squares method is that the system in this study is an overdetermined system, that is, a situation where there are more equations than unknowns. The $\mathrm{dP} 1$ in Table 4 includes two PDGEs and four PIGEs in the second position, $\mathrm{dP} 2$ includes two PDGEs and four PIGEs in the third position, and two more variables are added for each additional position measured. Therefore, assuming that the five 
rotation angles of the $\mathrm{C}$-axis are measured, there are10 PDGEs and 4 PIGEs. This paper uses two calibration spheres as the measurement standard. There are more equations $\mathrm{dP}$ than unknowns in the final system and this situation is very suitable for solving the variables using the least squares method.

Eq. (4) to Eq. (6) are ideal standard calibration spheres positions without error, and Eq. (7) to Eq. (9) are actual standard calibration spheres positions including errors. Since there is no error when $\mathrm{C}$-axis is $0^{\circ}, \theta_{c}$ of Eq. (4) to Eq. (6) is substituted with $0^{\circ}$, and it is named as $P^{i}\left(\theta_{c}=0^{\circ}\right)$, and the $\theta_{c}$ of Eq. (7) to Eq. (9) is substituted by any rotation angle to be measured by the $\mathrm{C}$-axis and name it as $P^{r}$. Subtracting Eq. (4) to Eq. (6) from Eq. (7) to Eq. (9), dP can be obtained as Eq. (10) to Eq. (12), where $\theta_{c}=0^{\circ}, \theta_{c 2}=$ any angle. Eq. (13) is the relationship between $P^{r}, P^{i}\left(\theta_{c}=0^{\circ}\right)$, and $\mathrm{dP}$.

$d P_{x}=O_{x c}+z_{s} S_{y c}-x_{s} \cos \left(\theta_{c}\right)+x_{s} \cos \left(\theta_{c 2}\right)+y_{s} C_{(p o s)} \cos \left(\theta_{c 2}\right)-y_{s} \sin \left(\theta_{c}\right)+y_{s} \sin \left(\theta_{c 2}\right)-x_{s} C_{(p o s)} \sin \left(\theta_{c 2}\right)$

$d P_{y}=O_{y c}-z_{s} S_{x c}-y_{s} \cos \left(\theta_{c}\right)+y_{s} \cos \left(\theta_{c 2}\right)-x_{s} C_{(p o s)} \cos \left(\theta_{c 2}\right)+x_{s} \sin \left(\theta_{c}\right)-x_{s} \sin \left(\theta_{c 2}\right)-y_{s} C_{(p o s)} \sin \left(\theta_{c 2}\right)$

$d P_{z}=C_{z(d e p)}+y_{s} S_{x c} \cos \left(\theta_{c 2}\right)-x_{s} S_{y c} \cos \left(\theta_{c 2}\right)-x_{s} S_{x c} \sin \left(\theta_{c 2}\right)-y_{s} S_{y c} \sin \left(\theta_{c 2}\right)$

$P^{r}=P^{i}\left(\theta_{c}=0^{\circ}\right)+d P$

Generally, when using the least squares method, the equation is expressed in matrix form, and the coefficients of the equation will be presented as $A_{6 n \times(4+2 n)}$ in Eq. (14), which becomes the form of the coefficient matrix multiplied by the row matrix of the error term. 
$d P_{k}=\left[\begin{array}{c}\mathrm{M} \\ d P_{x 1(\text { Ball } 1)} \\ d P_{y 1(\text { Ball } 1)} \\ d P_{z 1(\text { Ball } 1)} \\ d P_{x 1(\text { Ball } 2)} \\ d P_{y 1(\text { Ball } 2)} \\ d P_{z 1(\text { Ball } 2)} \\ \mathrm{M}\end{array}\right]_{6 n}=A_{6 n \times(4+2 n)} E_{\text {PIGEs }+ \text { PDGEs }}$

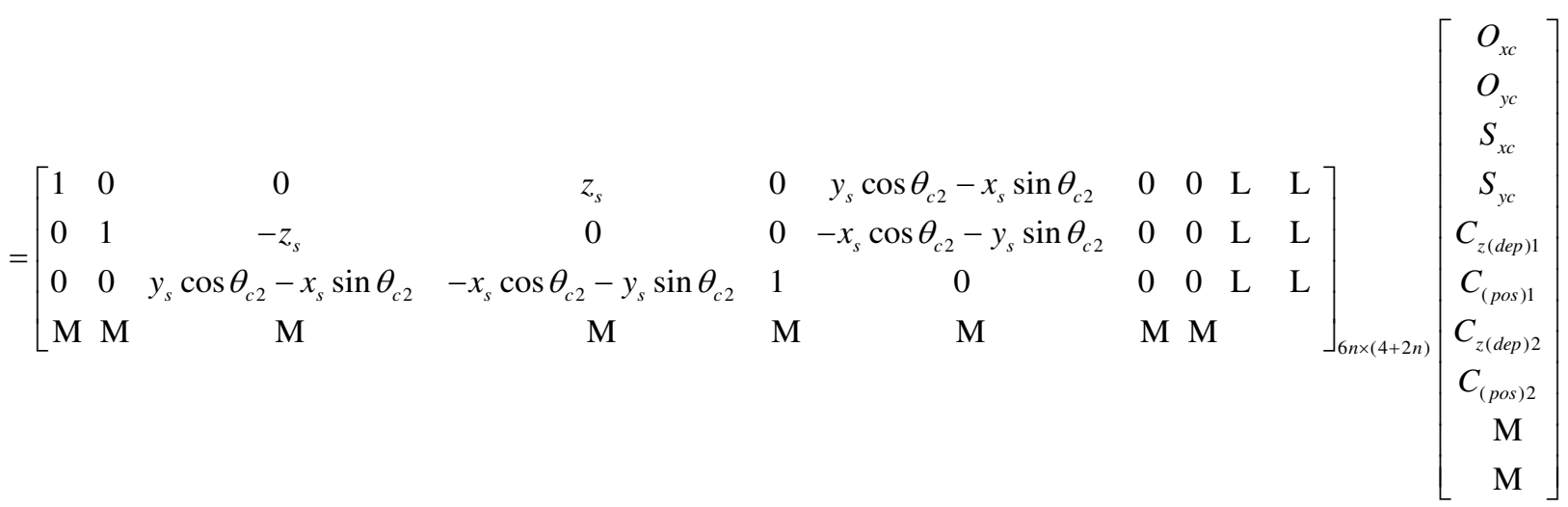

The research goal is to calculate $E_{\text {PIGES }+ \text { PDGES }}$. When there is a set of error values $E_{\text {PIGES }+ \text { PDGES }}$ that can minimize the sum of the squares of $(d P-A E)$ in Eq. (15), that is, the residual value, this set of values is the geometric error of this system. Eq. (15) is written in matrix form as Eq. (16).

$$
Q\left(E_{P I G E s+P D G E s}\right)=\frac{1}{s} \sum_{s=1}^{6 n}(d P-A E)^{2}=\frac{1}{s} \sum_{s=1}^{6 n} R_{s}^{2}
$$




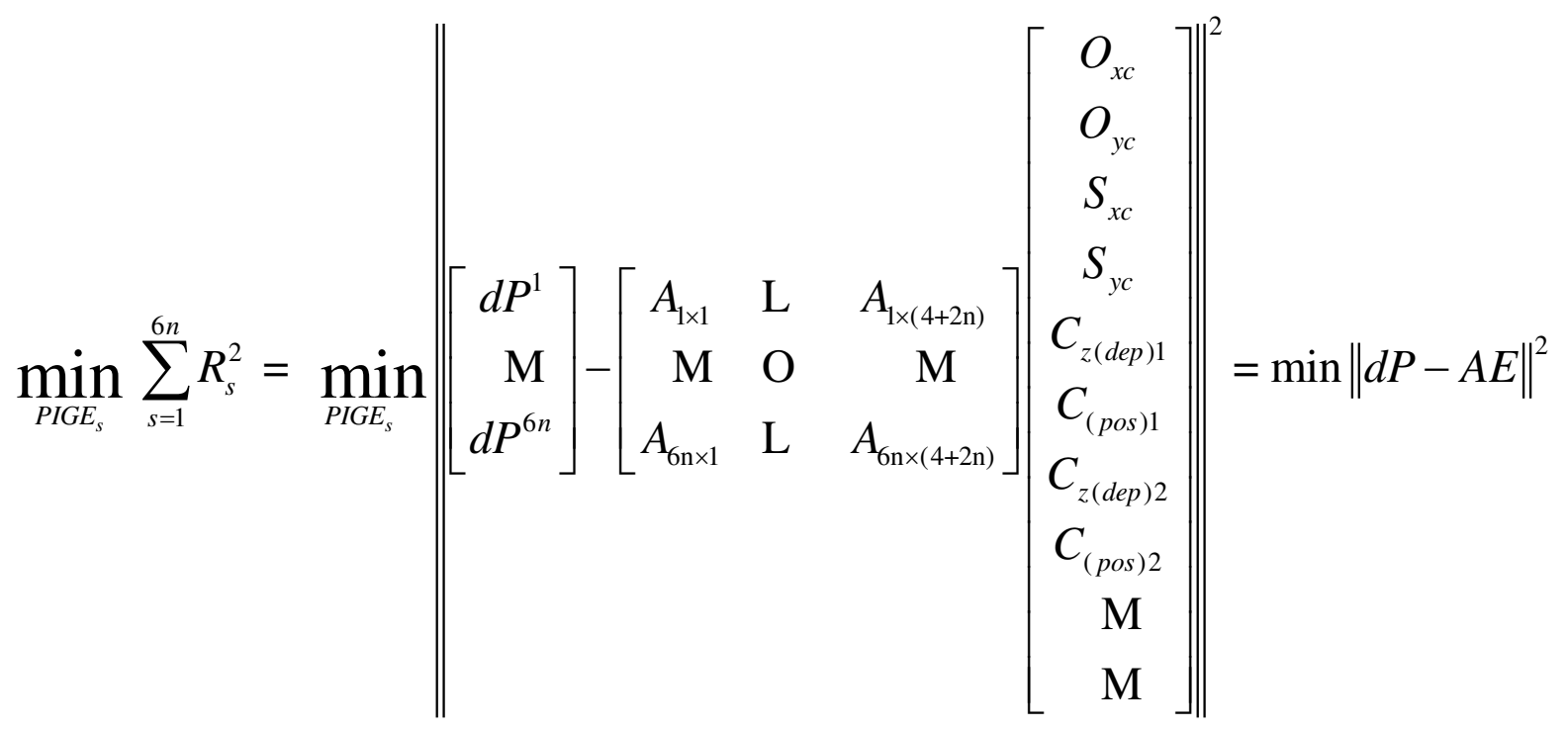

\subsection{Simulation of calculation method}

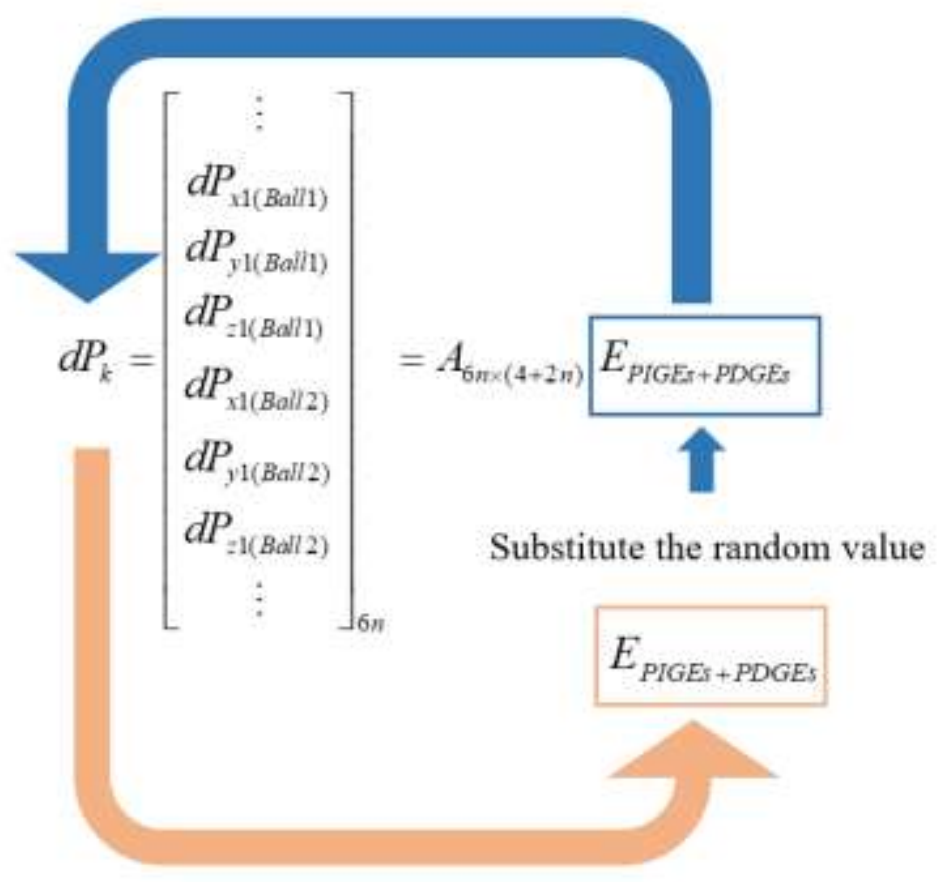

Fig. 13. Schematic diagram of error simulation.

In this section, simulations were used to verify the accuracy of the dP listed in section 4.2 and the error values obtained by the least squares method. In the simulation mode, the analyzed error variable in the equation was substituted by a random variable. Here, the error values were regarded as a known number. If the $\mathrm{dP}$ in Eq. (15) is based on experimental data, the $\mathrm{dP}$ was 
the result of subtracting the measured coordinates of standard calibration spheres. However, in the way of simulation, the simulated $\mathrm{dP}$ can be obtained without using experimental data by using random variables to substitute errors. Using the $\mathrm{dP}$ of this simulation and then using the least squares method to resolve the error values. Observing whether the random value assumed at the beginning and the parsed error result are the same or very close, as shown in Fig. 13. It can be found from Fig. 14 that the residual value obtained by subtracting the simulated random value and the analytical error is very small, and the residuals of all geometric errors are less than $10^{-10}$. From this simulation result, it can be known that the method of synchronous analysis of PIGEs and PDGEs in this paper is very accurate.

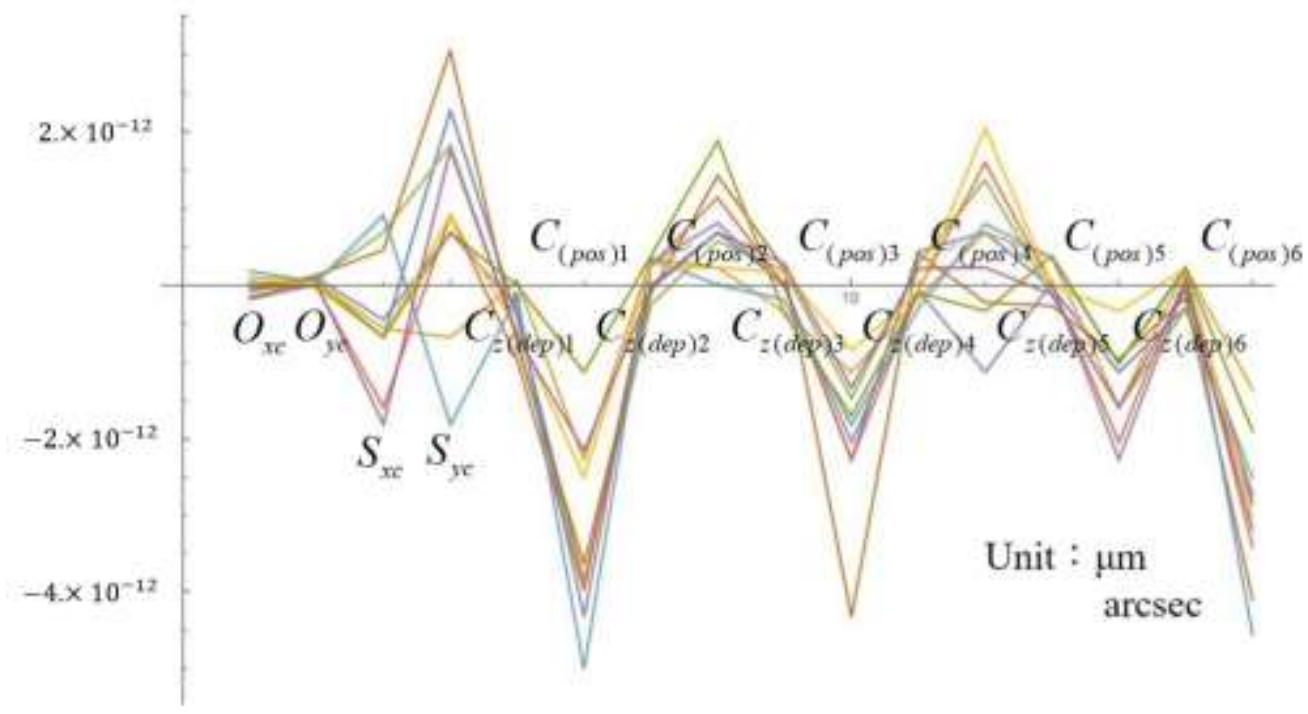

Fig. 14. Residual plot of error simulation.

\subsection{Measurement result}

In this experiment, the positions of 7 rotation angles of $\mathrm{C}$-axis were taken for error analysis. The measurement results are the average of 11 pieces of data. Table 6 and 7 are the measurement result of the PIGEs and PDGEs, respectively. The experiment has demonstrated feasibility of this measurement system.

Table 6. Error values of PIGEs.

\begin{tabular}{|c|c|c|c|c|}
\hline & $O_{x c}(\mu \mathrm{m})$ & $O_{y c}(\mu \mathrm{m})$ & $S_{x c}(\operatorname{arcsec})$ & $S_{y c}(\operatorname{arcsec})$ \\
\hline Average & 45.6046 & -158.3872 & -153.2539 & -95.1690 \\
\hline
\end{tabular}


Table 7. Error values of PDGEs.

\begin{tabular}{|c|c|c|}
\hline & $C_{z(d e p)}(\mu \mathrm{m})$ & $C_{(p o s)}(\operatorname{arcsec})$ \\
\hline & Average & Average \\
\hline $0^{\circ}$ & 0.0000 & 0.0000 \\
\hline$-15^{\circ}$ & -46.7580 & -144.7235 \\
\hline$-30^{\circ}$ & -43.0594 & -144.8288 \\
\hline$-45^{\circ}$ & -37.6213 & -149.7547 \\
\hline$-60^{\circ}$ & -30.2005 & -164.0565 \\
\hline$-75^{\circ}$ & -21.3915 & -176.5736 \\
\hline$-90^{\circ}$ & -11.7065 & -204.9957 \\
\hline
\end{tabular}

\section{Conclusions}

This paper has proposed the synchronous measurement of 4 PIGEs and 2 PDGEs of the rotary axis. Compared with previous studies, PIGEs and PDGEs are usually measured separately, but these two types of errors exist in the machine tools at the same time, and the step-by-step measurement essentially ignores the other type of geometric errors. Therefore, this paper improves the error measurement accuracy of the machine tools by considering the 4 PIGEs and 2 PDGEs at the same time, which is the contribution of this paper. And the measurement method proposed in this paper was actually applied to a five-axis machine tool This paper also verifies the accuracy of this measurement method from the point of view of mathematical simulation.

\section{Ethical Approval}

Not applicable.

\section{Consent to Participate}

Not applicable

\section{Consent to Publish}

Not applicable 


\section{Authors Contributions}

Ting-Yu Lee: Writing- Original draft preparation, Conceptualization, Methodology, Software, Validation. Yu-Ta Chen: Writing- Reviewing and Editing, Methodology. Chien-Sheng Liu: Writing- Reviewing and Editing, Supervision, Project administration.

\section{Funding}

The authors gratefully acknowledge the financial support provided to this study by the Ministry of Science and Technology of Taiwan under Grant Nos. MOST 110-2221-E-006-126MY3, 110-2218-E-006-031, and 110-2218-E-002-038.

\section{Competing Interests}

The authors have no financial or proprietary interests in any material discussed in this article.

\section{Availability of data and materials}

Not applicable

\section{Code availability}

Not applicable

\section{References}

[1] Y.-T. Chen, W.-C. Lin, C.-S. Liu, Design and experimental verification of novel six-degree- 
of freedom geometric error measurement system for linear stage, Optics and Lasers in Engineering, 92 (2016).

[2] C.-S. Liu, J.-Y. Zeng, Y.-T. Chen, Development of positioning error measurement system based on geometric optics for long linear stage, The International Journal of Advanced Manufacturing Technology, 115 (2021) 2595-2606.

[3] W. Gao, H. Haitjema, F. Fang, R. Leach, B.C.F. Cheung, E. Savio, J.-m. Linares, Onmachine and in-process surface metrology for precision manufacturing, CIRP Annals Manufacturing Technology, (2019).

[4] C.-C. Liu, M.-S. Tsai, M.-T. Lin, P.-Y. Tang, Novel multi-square-pulse compensation algorithm for reducing quadrant protrusion by injecting signal with optimal waveform, Mechanism and Machine Theory, 150 (2020) 103875.

[5] C.-S. Liu, H.-C. Hsu, Y.-X. Lin, Design of a six-degree-of-freedom geometric errors measurement system for a rotary axis of a machine tool, Optics and Lasers in Engineering, 127 (2020) 105949.

[6] D. Ma, J. Li, Q. Feng, Q. He, Y. Ding, J. Cui, Simultaneous Measurement Method and Error Analysis of Six Degrees of Freedom Motion Errors of a Rotary Axis Based on Polyhedral Prism, Applied Sciences, 11 (2021) 3960.

[7] C.-S. Liu, Y.-F. Pu, Y.-T. Chen, Y.-T. Luo, Design of a Measurement System for Simultaneously Measuring Six-Degree-Of-Freedom Geometric Errors of a Long Linear Stage, Sensors, 18 (2018) 3875.

[8] S. Ibaraki, T. Iritani, T. Matsushita, Calibration of location errors of rotary axes on five-axis machine tools by on-the-machine measurement using a touch-trigger probe, International Journal of Machine Tools and Manufacture, 58 (2012) 44-53.

[9] C. Liu, S. Xiang, C. Lu, C. Wu, Z. Du, J. Yang, Dynamic and static error identification and separation method for three-axis CNC machine tools based on feature workpiece cutting, The International Journal of Advanced Manufacturing Technology, 107 (2020) 2227-2238.

[10] R. Ramesh, M.A. Mannan, A.N. Poo, Error compensation in machine tools - a review: Part I: geometric, cutting-force induced and fixture-dependent errors, International Journal of Machine Tools and Manufacture, 40 (2000) 1235-1256.

[11] F. Tan, G. Yin, K. Zheng, X. Wang, Thermal error prediction of machine tool spindle using segment fusion LSSVM, The International Journal of Advanced Manufacturing Technology, 116 (2021) 99-114.

[12] V.S.B. Kiridena, P.M. Ferreira, Kinematic modeling of quasistatic errors of three-axis machining centers, International Journal of Machine Tools and Manufacture, 34 (1994) 85-100.

[13] H. Shen, J. Fu, Y. He, X. Yao, On-line Asynchronous Compensation Methods for static/quasi-static error implemented on CNC machine tools, International Journal of Machine Tools and Manufacture, 60 (2012) 14-26. 
[14] Q. Xiong, Q. Zhou, Development Trend of NC Machining Accuracy Control Technology for Aeronautical Structural Parts, World Journal of Engineering and Technology, 08 (2020) 266-279.

[15] D. Papageorgiou, M. Blanke, H.H. Niemann, J.H. Richter, Adaptive and sliding mode friction-resilient machine tool positioning - Cascaded control revisited, Mechanical Systems and Signal Processing, 132 (2019) 35-54.

[16] F. Tan, G. Yin, K. Zheng, X. Wang, Correction to: Thermal error prediction of machine tool spindle using segment fusion LSSVM, The International Journal of Advanced Manufacturing Technology, 116 (2021) 115-115.

[17] S. Ibaraki, H. Inui, C. Hong, S. Nishikawa, M. Shimoike, On-machine identification of rotary axis location errors under thermal influence by spindle rotation, Precision Engineering, 55 (2018).

[18] Y. Liu, Identification of position independent geometric errors of rotary axes for five-axis machine tools with structural restrictions, Robotics and Computer-Integrated Manufacturing, 53 (2018).

[19] S. Xiang, J. Yang, Y. Zhang, Using a double ball bar to identify position-independent geometric errors on the rotary axes of five-axis machine tools, The International Journal of Advanced Manufacturing Technology, 70 (2014).

[20] Q. Li, W. Wang, J. Zhang, H. Li, All position-dependent geometric error identification for rotary axes of five-axis machine tool using double ball bar, The International Journal of Advanced Manufacturing Technology, 110 (2020) 1351-1366.

[21] Y.-T. Chen, P. More, C.-S. Liu, C.-C. Cheng, Identification and compensation of positiondependent geometric errors of rotary axes on five-axis machine tools by using a touchtrigger probe and three spheres, The International Journal of Advanced Manufacturing Technology, 102 (2019).

[22] S. Ibaraki, T. Iritani, T. Matsushita, Error map construction for rotary axes on five-axis machine tools by on-the-machine measurement using a touch-trigger probe, International Journal of Machine Tools and Manufacture, 68 (2013) 21-29.

[23] L. Jiakun, F. Qibo, B. Chuanchen, Y. Jing, Z. Bintao, Measurement method and error analysis for angular positioning error of rotary axis, Infrared and Laser Engineering, 48 (2019) 217001.

[24] W. Fang, X. Tian, Geometric error sensitivity analysis for a 6-axis welding equipment based on Lie theory, The International Journal of Advanced Manufacturing Technology, 113 (2021) 1045-1056.

[25] J.H. Jeong, G. Khim, J.S. Oh, S.-C. Chung, Method for measuring location errors using a touch trigger probe on four-axis machine tools, The International Journal of Advanced Manufacturing Technology, 99 (2018) 1003-1012.

[26] Y.-T. Chen, P. More, C.-S. Liu, Identification and verification of location errors of rotary 
axes on five-axis machine tools by using a touch-trigger probe and a sphere, The International Journal of Advanced Manufacturing Technology, 100 (2019).

[27] S. Ibaraki, I. Yoshida, T. Asano, A machining test to identify rotary axis geometric errors on a five-axis machine tool with a swiveling rotary table for turning operations, Precision Engineering, 55 (2019) 22-32.

[28] Z. Li, R. Sato, K. Shirase, S. Sakamoto, Study on the influence of geometric errors in rotary axes on cubic-machining test considering the workpiece coordinate system, Precision Engineering, 71 (2021) 36-46.

[29] Z. Jiang, X. Tang, X. Zhou, S. Zheng, Machining tests for identification of location errors on five-axis machine tools with a tilting head, The International Journal of Advanced Manufacturing Technology, 79 (2015) 245-254.

[30] F. Viprey, H. Nouira, S. Lavernhe, C. Tournier, Modelling and characterisation of geometric errors on 5-axis machine-tool, Mechanics \& Industry, 20 (2019) 605.

[31] Y. Abbaszadeh-Mir, J.R.R. Mayer, G. Cloutier, C. Fortin, Theory and simulation for the identification of the link geometric errors for a five-axis machine tool using a telescoping magnetic ball-bar, International Journal of Production Research, 40 (2002) 4781-4797.

[32] ISO 230-1, in: Test code for machine tools - Part 1: Geometric accuracy of machines operating under no-load or quasi-static conditions, 2012.

[33] ISO 230-7, in: Test code for machine tools - Part 7: Geometric accuracy of axes of rotation, 2015. 